\title{
Fotografia criativa para as crianças: a alfabetização audiovisual através da fotografia
}

María del Mar Ramírez Alvarado

Doutora em Ciências da Informação. Professora da Faculdade de Comunicaşão da Universidade de Sevilha-ES.

E-mail: delmar@us.es

Virginia Guarinos Galán

Doutora em Ciências da Informação e em Filologia. Diretora do Departamento de Comunicação Audiovisual e Publicidade da Faculdade de Comunicação da Universidade de Sevilha-ES.

E-mail: guarinos@us.es

Inmaculada Gordillo Álvarez

Doutora em Ciências da Informação. Professora da Faculdade de Comunicação da

Universidade de Sevilha-ES.

E-mail: ingoal@us.es

Jacqueline Sánchez Carrero

Doutora em Comunicaşão pela Universidade de Sevilla (Espanha).

Mestra em Comunicação Audiovisual na área ibero-americana (Universidad Internacional de Andalucía (Espanha). Professora da Universidade de Huelva - ES.

E-mail: jsanchezcarrero@gmail.com

Resumo: $\mathrm{O}$ artigo apresenta os resultados das Oficinas de Fotografia para crianças entre 4 e 12 anos, realizadas em Sevilha (Espanha), através de sessões que tinham por objetivo desenvolver nas crianças, desde tenra idade, a capacidade de compreender e produzir imagens fotográficas, reconhecendo nelas um meio privilegiado de expressão artística, comunicação e informação. A experiência demonstrou que as crianças são capazes de interiorizar noções básicas sobre planos, ângulos, perspectiva, sequências e composição. Também desenvolveram habilidade para realizar enquadramentos, selecionar temas, observar a iluminação etc. A fotografia demonstrou ser também uma eficaz ferramenta de aproximação das crianças a diversas manifestações culturais.

Palavras-chave: fotografia, alfabetização audiovisual, linguagem audiovisual, infância.
Abstract: This article presents the results of Photography Workshops for Children between 4 and 12 years performed in Seville (Spain) through sessions with the aim of developing early age, the ability to understand and produce photographic images recognizing them a privileged means of artistic expression, communication and information. Experience has shown that children are able to internalize basic concepts such as planes, angles, perspecti$v e$, and composition sequences. They also develop their ability to perform framing, selecting motifs, watch the lighting etc. The photography proved to be also a powerful tool for approximation of children to various cultural events.

Keywords: photography, audiovisual literacy, audiovisual language, childhood.
Recebido: 20.06 .2010 
comunicação \& educação • Ano XV • número 3 • set/dez 2010

As fotos são imagens criadas pelo ser humano para imortalizar, de alguma forma, sua existência, a daqueles que o cercam e do seu entorno. Desde sua invenção, a fotografia é um meio de representação de grande importância, além de ser um instrumento determinante na comunicação diária com enormes possibilidades de utilização como recurso dinamizador da aprendizagem em diversas áreas do conhecimento, inclusive as artes e a comunicação.

Neste artigo, apresentamos o resultado do projeto Oficinas de Fotografia Criativa para Crianças que, partindo das possibilidades deste meio como recurso educacional, foram realizadas no Colégio de Educação Infantil e Primária José María del Campo, em Sevilha, e na Faculdade de Comunicação da Universidade de Sevilha, entre novembro de 2008 e janeiro de 2009. Esta iniciativa, subvencionada pela Empresa Pública de Gestão de Programas Culturais do Conselho de Cultura da Junta de Andaluzia, através de seu edital Iniciarte, teve como objetivo desenvolver nas crianças, desde a tenra idade, a capacidade de compreender, criar e produzir imagens fotográficas, reconhecendo na fotografia um meio privilegiado de expressão artística, de comunicação e de informação.

No total, foram realizadas três oficinas. No Colégio José María del Campo participaram dois grupos de crianças de 4 e 5 anos, correspondendo ao terceiro ano da Educação Infantil, totalizando 50 alunos. $\mathrm{O}$ grupo estudado na Faculdade de Comunicação era integrado por estudantes com idades que variavam de 4 a 12 anos de idade. Os conteúdos foram expostos através de aulas primordialmente práticas (os participantes trabalhavam com as câmeras em duplas), de um alto teor lúdico, que tratavam dos seguintes aspectos:

- Sessão 1: O que é a fotografia? Análise e descrição de fotografias: publicidade, fotojornalismo, fotografias artísticas e da natureza.

- Sessão 2: A câmera fotográfica. A mesma realidade, enfoques diversos: visão, ângulo e enquadramento. Os planos em fotografia.

- Sessão 3: O álbum de família: assim éramos quando pequenos, assim é nossa família. O autorretrato.

- Sessão 4: Da imagem física à imagem em movimento. Os diversos tipos de imagens: quadrinhos, pinturas (realistas e abstratas), hologramas, sinais convencionais.

- Sessão 5: Descobrimos outras culturas.

- Sessão 6: Expedições de reconhecimento: "Descobrimos nosso entorno". A iluminação.

- Sessão 7: Contamos contos através de fotografias.

- Sessão 8: Minhas fotos: Exposição "Pequenos fotógrafos". Encontro com os pais.

Com relação a este último tópico, realizou-se, na Faculdade de Comunicação da Universidade de Sevilha, a I Mostra de Fotografia Realizada por Crianças: o Olho Mágico, que reuniu trabalhos dos participantes das oficinas. A mostra ocorreu ao longo de todo o mês de fevereiro, como parte das comemorações do vigésimo aniversário da Faculdade de Comunicação. No total, foram expostas 69 fotografias selecionadas do material produzido pelas crianças nas 
três oficinas. Posteriormente, a mostra foi levada ao Colégio José Maria del Campo, no bairro sevilhano de Triana, também como atividade comemorativa do centenário daquela instituição.

A equipe de professores foi formada por Jacqueline Sánchez-Carrero, especialista em alfabetização audiovisual infantil, por Virginia Guarinos, Inmaculada Gordillo e Mar Ramírez Alvarado, todas doutoras, professoras universitárias e integrantes do Grupo de pesquisa sobre análise de mídia, imagens e relatos e relatos audiovisuais (Admira).

\section{A IMPORTÂNCIA DA ALFABETIZAÇÃO AUDIOVISUAL. A FOTOGRAFIA COMO FERRAMENTA DIDÁTICA}

Quando, em 1826, Nicéphore Niepce, o pai da fotografia, plasmou a primeira imagem já de forma permanente com seu pequeno aparelho captador de imagens, não podia imaginar que com o decorrer do tempo aquele seu invento seria utilizado até por crianças em idade pré-escolar. E eis que a câmera fotográfica é em nossos dias uma ferramenta de uso popular que nunca perdeu seu valor artístico e pedagógico.

A alfabetização audiovisual tem por objetivo instruir o aluno tanto na parte técnica quanto na semântica do meio audiovisual. Nesse sentido, a fotografia pode ser entendida como um dos primeiros recursos, e fundamental para a compreensão do que significa a imagem. Sem dúvida, aprender a ver é um processo que se origina através do uso didático da visão, a qual, por sua vez, é um dos sentidos primordiais que colocamos em funcionamento como seres humanos: antes de aprender a falar, olhamos. É possível educar o modo de ver? Quando se aprende a fotografar criativamente, está se preparando a visão, entre outras coisas, para escolher um tema, circunscrever o essencial e captar a carga emocional que uma determinada situação nos transmite.

Toda imagem encarna um modo de ver. Inclusive a fotografia, pois as fotos não são, como se costuma supor, um mero registro mecânico. A cada vez que olhamos uma foto somos conscientes, mesmo que de maneira tênue, de que o fotógrafo escolheu aquela vista entre uma infinidade de outras possíveis. Isso é verdade inclusive para o mais despretensioso instantâneo familiar¹.

Sem dúvida, é na infância quando melhor se pode aprender a educar o olhar. Durante as oficinas, o primeiro ponto que chamou a atenção foram as expressões de assombro quando as crianças tiveram nas mãos uma câmera fotográfica de verdade, e não para brincar, mas para tiras fotos reais, aquelas que comporiam no final uma exposição destinada a todos os públicos. Como explicar para crianças de 4 e 5 anos o que é uma câmera fotográfica? O conceito de caixa mágica foi bastante útil. Descrever os diferentes tipos de imagens que podem ser captadas foi também uma etapa simples. As crianças compreenderam as diferenças entre fotos para publicidade, para o jornalismo e as fotos da natureza.

1. BERGER, J. Modos de ver. Barcelona: Gustavo Gili, 2007. p. 16. 
A ideia de aprender a ver, a olhar através de um dispositivo, foi exemplificada mediante a construção de uma câmera por parte dos pequenos participantes. O procedimento de transformar uma embalagem de isopor (de hambúrguer) em uma câmera artesanal foi divertido e surpreendente. Olhar através de um furo situou-os no papel do fotógrafo. Esta tarefa serviu para mostrar às crianças o processo de composição.

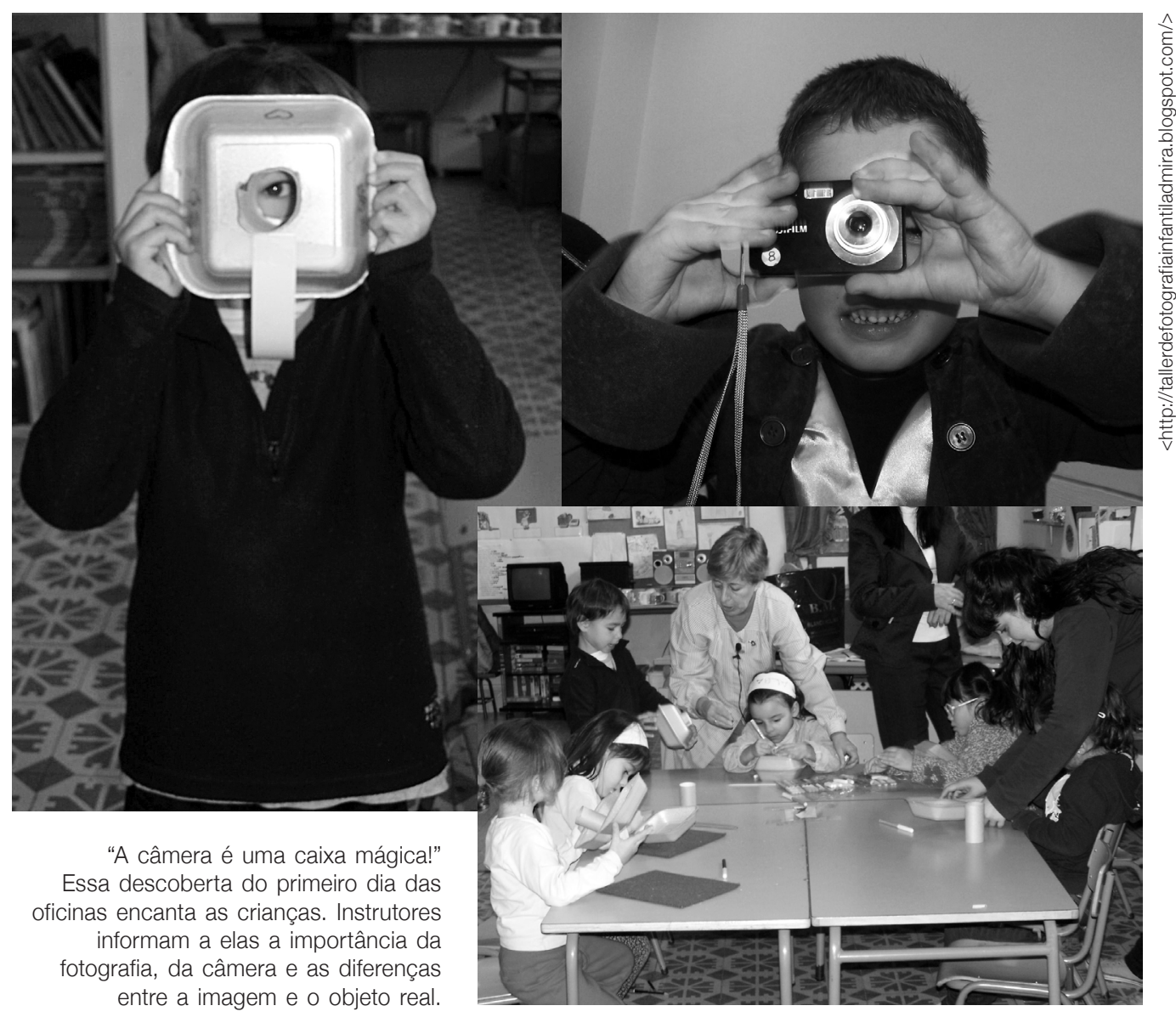

Nessa fase, a fotografia é um recurso de alfabetização inigualável. Fazer a composição é organizar os elementos que formam a imagem em sua totalidade. Olhar pelo visor de uma máquina obriga de algum modo a selecionar elementos, a cuidar dos vazios e a direcionar a visão para o mais importante. Em uma das práticas, as crianças fotografaram livremente umas às outras. Notou-se, curiosamente, que uma imagem que se repetia com frequência era a da boca aberta de muitos deles. Por não terem ainda aprendido a utilizar o recurso do zoom, as crianças se aproximavam tanto da câmera que terminavam por captar o interior da boca em meio a animadas risadas. Começavam então a compreender que com a câmera podiam tirar fotos de lugares que antes não haviam imaginado.

Outro aspecto interessante no processo de alfabetização da imagem é o fato de as crianças desejarem conhecer a câmera antes de escutar qualquer outra 
Fotografia criativa para as crianças - M. Alvarado, V. Galán, I. Álvarez e J. Carrero

explicação. Como é natural, pretendia-se mostrar a estrutura geral da câmera parte por parte, mas o interesse delas recaía em utilizar o disparador e ver o mundo; muitas tinham se adiantado e já sabiam até como ver a fotografia realizada. Este processo foi proveitoso na medida em que podiam verificar se o plano alcançado era o plano que pretendiam fazer. Logicamente, para aquele momento, os planos principais (geral, americano, médio, primeiro plano e plano detalhe) já tinham um lugar em sua memória. Apesar de esta terminologia ser uma novidade para elas, os exemplos empregados para identificar a taxonomia dos planos surtiram efeito em sua memória. É preciso que sejam imagens ou gráficos que chamem a atenção das crianças e que descrevam explicitamente o significado do plano em questão. O autorretrato é, por outro lado, uma atividade quase cotidiana dos adolescentes na atualidade, seja para colocar na internet, seja para usar no celular; é fácil encontrar imagens de garotos e garotas que se autofotografam, sozinhos ou com amigos. No caso dos menores, essa atividade chamou sugestivamente a atenção, pois não pensavam que eles mesmos pudessem se retratar e, o que é ainda melhor, não sabiam que gesto fazer diante da câmera, pois não tinham a possibilidade de olhar na tela. Foram bastante engenhosos e utilizaram os objetos que refletiam, tais como espelhos, vidros ou elementos metálicos.

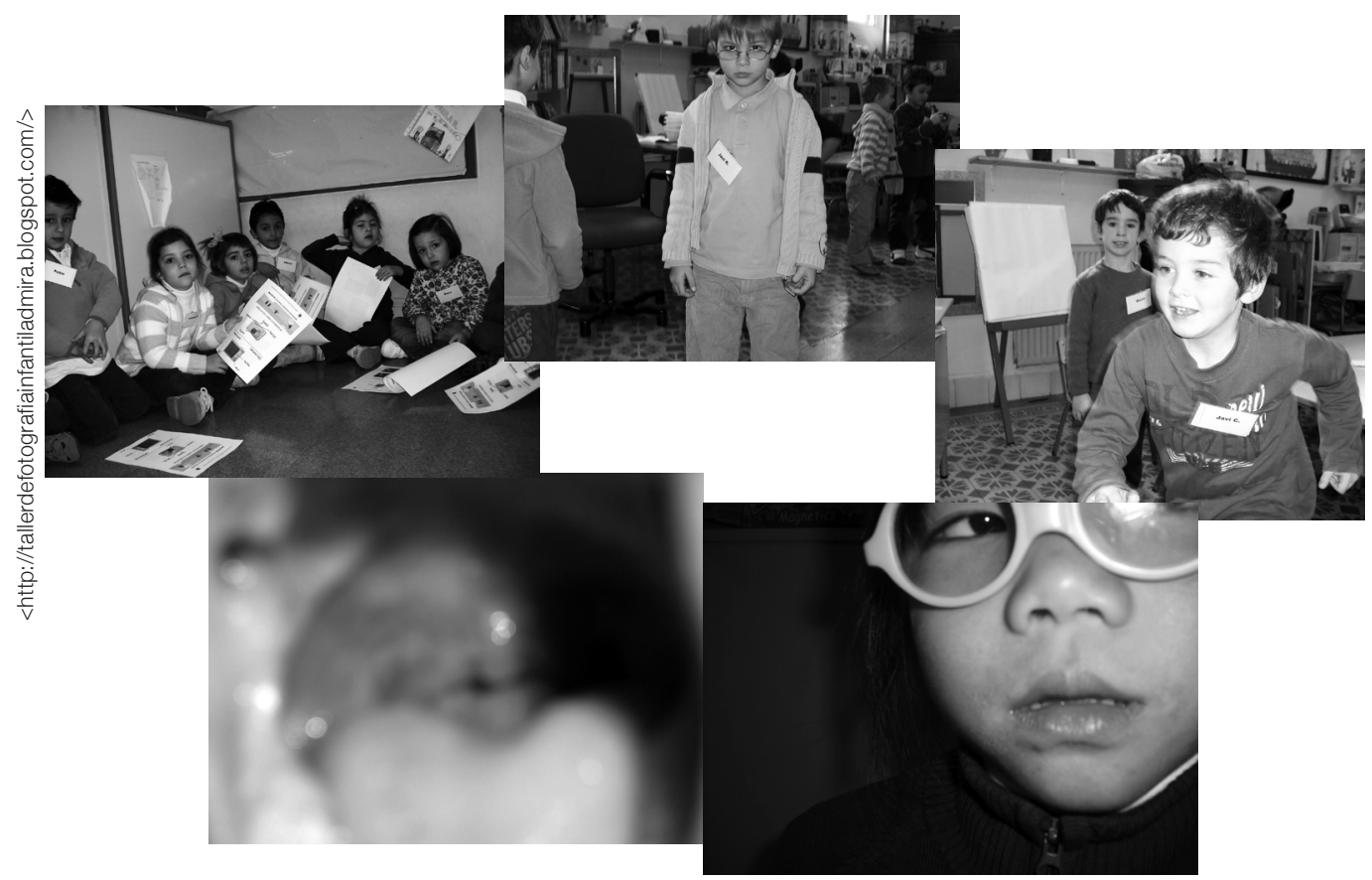

As imagens realizadas pelas crianças em sentido horário:

Plano Geral, Plano Americano, Plano Médio, Primeiro Plano e... uma tentativa de Plano Detalhado.

Da imagem fixa podem ser aprendidos vários aspectos como, por exemplo, o enquadramento, a cor ou o efeito de luz e sombra que se podem produzir nela. Não obstante, não quisemos deixar passar a oportunidade de mostrar o que é a imagem fixa em relação à imagem em movimento. Os jogos óticos prestam-se 
* O taumatroscópio foi um dos mais antigos e populares brinquedos de animação. Consiste num pequeno disco preso a dois cordões em lados opostos. Em cada uma das faces do disco existe uma imagem diferente. Quando o disco é girado pelas mãos do espectador, as duas imagens se fundem em uma única. O zootrópio ou roda da vida foi criado em torno de 1834 pelo relojoeiro inglês William Horner. Trata-se de um tambor giratório com frestas em toda a sua circunferência. Em seu interior, montavam-se sequências de imagens produzidas em tiras de papel, de modo que cada imagem estivesse posicionada do lado oposto a uma fresta. Ao girar o tambor, olhando através das aberturas, assiste-se ao movimento. N.E.

2. CAMPS, V. La educación en medios, más allá de la escuela (A educação através da mídia, além da escola). Revista Comunicar, 32, p. 139, 2009 magnificamente para explicar tal processo. As crianças se aproximaram admiradas diante de diferentes elementos de ilusão de ótica como o livro animado, o taumatroscópio ou o zootrópio*, e viram como a mudança abrupta de uma imagem fixa a outra com mudanças imperceptíveis produzia a imagem em movimento. Inclusive, coloriram uma tira de papel para zootrópio na qual apareciam cenas divertidas como um mago tirando um coelho da sua cartola. Apesar de ser um tema de difícil compreensão para crianças tão pequenas, foi muito útil em tal situação para iniciá-las no caminho da alfabetização pela imagem.

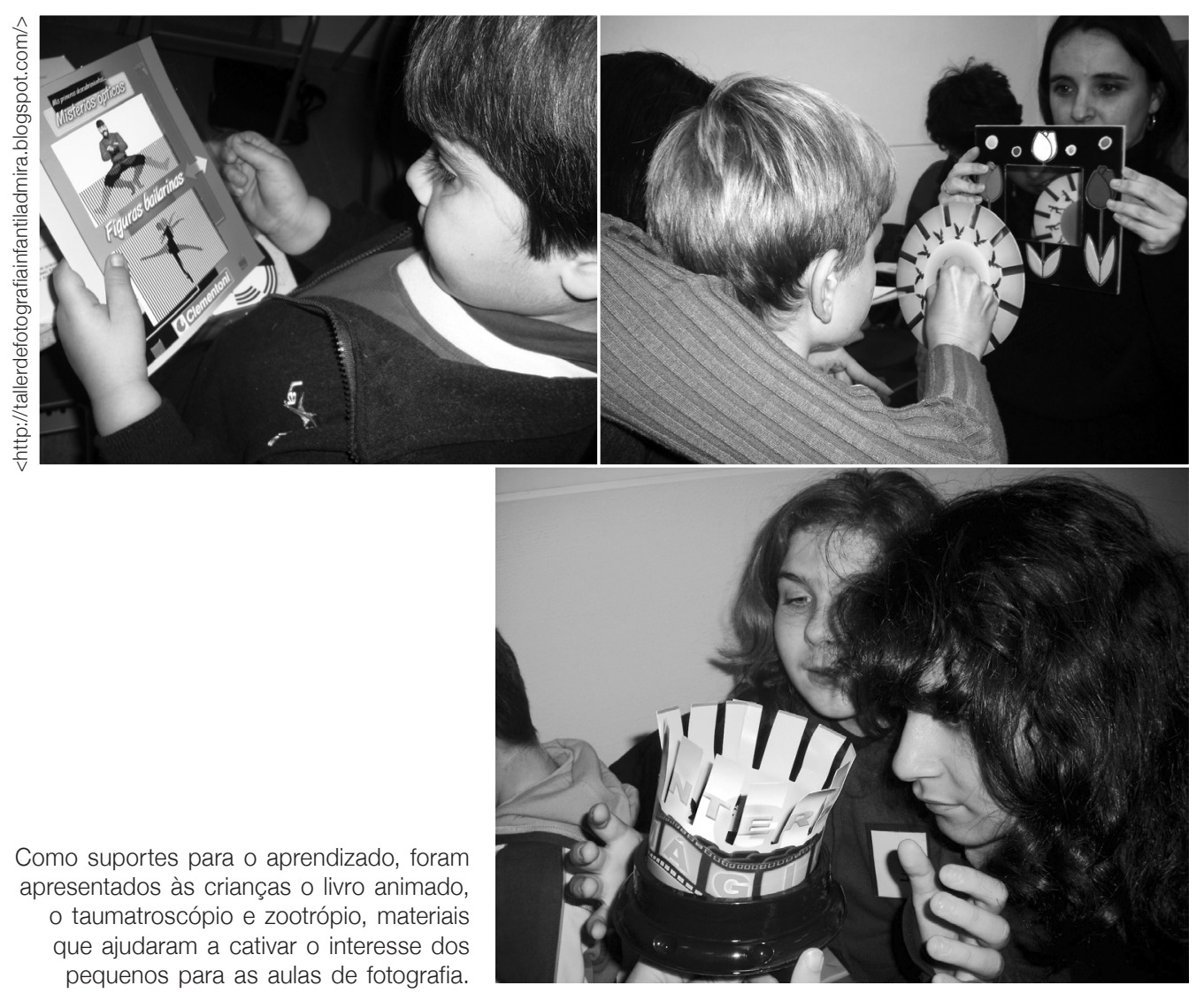

É notório o recente interesse, por parte de instituições de âmbito internacional, em educar o olhar da criança para os meios audiovisuais. Mas tal alfabetização vai além e deve considerar não apenas os valores tecnológicos e econômicos, como também os sociais, democráticos e civis do cidadão ${ }^{2}$. $\mathrm{O}$ ensino da fotografia contribui muito nesse sentido. Existem exemplos dignos de nota que explicam o uso positivo da fotografia na infância. Um deles é o de Zana Briski, fotojornalista, que em 2002 viajou para o Bairro Vermelho de Calcutá (Índia) para realizar uma reportagem sobre a vida das prostitutas e dos seus filhos. Foi tamanho o impacto que lhe causou a realidade daquelas crianças, que deu a elas câmeras e ensinou-as a usá-las aplicando alguns fundamentos estéticos. O resultado de todo o processo educacional e artístico foi o documentário As crianças do Bairro Vermelho [Born into brothels: Calcutta's 
Fotografia criativa para as crianças - M. Alvarado, V. Galán, I. Álvarez e J. Carrero

Red Light kids], que ganhou o Oscar de Melhor Documentário em longa-metragem dois anos depois. Através da fundação Kids with cameras $^{3}$, ela ofereceu às crianças a possibilidade de ir à escola numa tentativa de fazer valerem seus direitos e tirá-las da pobreza. De forma que a fotografia não é apenas uma ferramenta didática, mas pode ir além, influenciando de forma eficaz na construção da autoestima dos menores, o que, cedo ou tarde, se refletirá numa sociedade melhor.

\section{CONTAR HISTÓRIAS ATRAVÉS DA FOTOGRAFIA}

Quando a criança aprende as noções básicas de composição de imagens, ela detém o núcleo teórico básico para enfrentar o desafio de contar histórias através da fotografia, ação que pode não ser fácil nem mesmo para um adulto. A construção de um relato, independentemente do sistema de signos com o qual seja realizada, é algo aprendido na primeira infância. De um modo instintivo, os pequenos assimilam a estrutura narrativa clássica de apresentação, nó e desenlace a partir da narração oral com a qual os familiares e professores constroem os discursos que contam a elas.

No contexto das oficinas, foi oferecida às crianças a adaptação da Poética de Aristóteles sobre apresentação, nó e desenlace, transformados em começo do conto, o que aconteceu depois e final do conto, seguindo as sugestões da série didática Danny E् Daddy. Imagine. Expressão Escrita. Gosto de escrever contos [Danny $\mathcal{E}$ Daddy. Imagina. Expresión escrita. Me gusta escribir cuentos], elaborados pelo Conselho de Educação da Comunidade Valenciana ${ }^{4}$.

Também foram empregados materiais didáticos sobre a dramatização de contos, como os de Encabo \& Jerez ${ }^{5}$ e Encabo \& López $^{6}$, e seguimos as indicações para o ensino de fotografia em níveis de educação primária, baseadas nas experiências prévias, como as de Rodríguez Barbero ${ }^{7}$ (2001).

Com tal base teórico-prática, as sessões que desenvolveram a experiência seguiram a estrutura seguinte.

Explicações teóricas:

- Sobre a narração de contos infantis. Através de exemplos, estabeleceram-se as três fases do desenvolvimento de uma história em exposição, nó e desenlace, assim como as categorias básicas da narrativa: quem, o que, quando, como, onde, por quê. A prática foi realizada a partir de Branca de Neve, Chapeuzinho Vermelho e Os três porquinhos.

- Sobre a fotografia sequencial. O primeiro objetivo foi a fotografia sequencial sem movimento, com diversas fotos em diferentes enquadramentos de um objeto móvel. Em seguida, foram mostrados vários exemplos de fotografia sequencial com sugestão de movimento, inclusive algumas das pioneiras de Edward Muybridge (os acrobatas).

Atividades práticas:

- Ordenação de histórias. Tal como quebra-cabeças de contos, foram entregues às crianças historinhas com os quadrinhos recortados fora de

3. Fundação Kids with Cameras. Disponível em: <http://www.kids-with-cameras.org/bornintobrothels/film.php>.

4. Direção-Geral de Avaliação, Inovação e Qualidade Educativa e de Formação Profissional. Os materiais encontram-se disponíveis em: <http:// www.escolalliurex.com $>$ e <http://www.funcae.es/ $\mathrm{id} /$ castellano/02/D\&D/ Imagina.pdf $>$.

5. ENCABO, E. y JEREZ, I. La dramatización como arte creativa: los cuentos de Hans Christian Andersen y la Didáctica de la Literatura (A dramatização como arte criativa: os contos de Hans Christian Andersen e a didática da literatura). Primeras Noticias: revista de Literatura, n. 209, p. 65-72, 2005.

6. ENCABO, E. y LÓPEZ VALERO, A. (Coord.). Didáctica de la literatura: el cuento, la dramatización y la animación a la lectura (Didática da literatura: o conto, a dramatização e a animação para a leitura). Barcelona: Octaedro Editorial, 2004.

7. RODRÍGUEZ BARBERO,

A. Didáctica de la foto grafía: enseñanza de la fotografía en los niveles de Educación Infantil y Primaria (Didática da fotografia: ensino de fotografia na Educação Infantil e Primária). Revista de Educación de la Universidad de Granada, 14, p. 107-118, 2001. 
comunicação \& educação • Ano XV • número 3 • set/dez 2010

ordem, para que elas ordenassem até encontrar sentido. Seis quadrinhos para os maiores, três para os menores.

- Criação oral de um conto esquemático coletivo, selecionando os três momentos correspondentes ao princípio, fim e nó. ${ }^{8}$

- Divisão dos alunos em grupos. Foram oferecidos figurinos para a construção de histórias de piratas, romanos, cowboys, princesas e festas à fantasia.

- Desenvolvimento de uma história particular de cada grupo com seleção dos três momentos que seriam fotografados.

- Fotografia da encenação. Enquanto os membros de um grupo trabalhavam como atores, os de outro grupo atuavam como fotógrafos. Desse modo, todas as crianças fizeram, com vários disparos, três fotos dos três momentos importantes de cada conto.

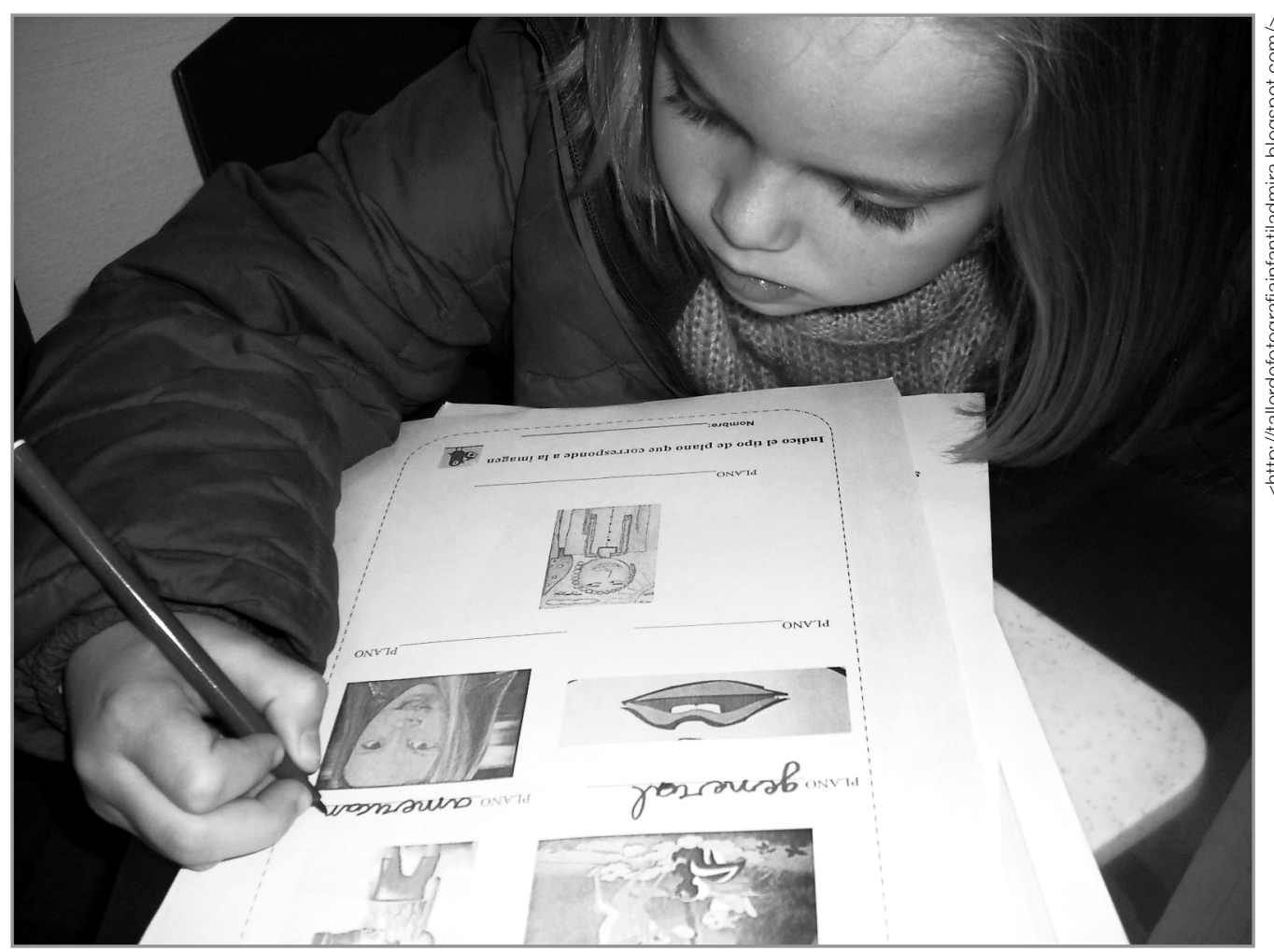

Da Poética de Aristóteles à organização da foto, crianças aprendem a manipular a câmera,

a diferenciar elementos básicos da composição da imagem e a contar uma história através da fotografia.

8. Foi indicado a eles um site para que pudessem praticar em casa, La máquina de hacer cuentos (A máquina de fazer contos). Disponível em: <http:// ciencias.huascaran.edu. pe/modulos/m_pancho/ index.htm>.
Sem refletir sobre isto, todas as crianças foram capazes de organizar uma história nuclear com um começo, um meio e um final. Também não deu muito trabalho para elas imaginar um plano de imagem fixa que representasse esses três momentos de uma história. Entretanto, as sugestões de movimento e tempo eram frequentes em suas intervenções, sendo preciso lembrá-las a todo momento que em uma fotografia ou em um cartaz não é possível incluir tais noções de tempo e movimento, assim como desejavam fazer. A dificuldade se apresentou no momento de colocar em prática o ordenamento da sequência da história em três 
Fotografia criativa para as crianças - M. Alvarado, V. Galán, I. Álvarez e J. Carrero

ou quatro fotografias que representassem aqueles momentos selecionados como núcleos de histórias simples. As crianças com mais de 10 anos foram capazes de organizar a história por completo e sem ajuda, mas tiveram dificuldade na hora de escolher as três cenas em planos diferentes do plano geral. Em alguns casos, recorreram ao plano picado (a cena é vista de cima para baixo), e ao contrapicado (a cena é vista de baixo para cima) como possíveis pontos de vista sobre a cena, ou ao zoom para compor planos mais curtos que mostrassem apenas partes da cena. Daí se deduz que tiveram problema diante da possibilidade de organizar um relato, selecionando elementos parciais sobre a encenação geral montada ex profeso. Os menores de 10 anos ficaram um passo atrás: não conseguiram de forma independente se organizar para colocar em cena o conto construído oralmente por eles mesmos, em grupos de 4 a 5 crianças.

Em linhas gerais:

- Todos possuem a capacidade de construir textos orais.

- Apenas os maiores de 10 anos possuem a capacidade de representar uma encenação de tais reais relatos.

- Nenhum deles conta com a capacidade para captar fotograficamente em sequência a encenação.

Podemos entender, portanto, que a ordenação de uma ficção em imagens fixas é um processo complexo para o qual não está ainda apto o desenvolvimento cognitivo de uma criança menor de 12 anos, como no caso de crianças tão pequenas como as que participaram das Oficinas de Fotografia Criativa. Existe uma dificuldade manifestada por elas no plano fixo sem movimento nem temporalidade, pensado para ser encadeado com outro em uma continuidade, em uma serialização. Esta conclusão corrobora as experiências anteriores em matéria de sequencialidade literária, que provocaram a generalização de materiais didáticos pensados para a aprendizagem de escritura de contos que citamos no começo desta seção. A elaboração de tal material foi motivada por outro exercício realizado com alunos de terceiro ano primário (de 8 a 9 anos), os quais mostraram uma dificuldade geral com a descrição por escrito baseada em sequências integradas por três desenhos.

\section{A FOTOGRAFIA COMO RECURSO PARA A APROXIMAÇÃO A OUTRAS CULTURAS}

Ao passo que a criança aprende a manipular a câmera, a diferenciar elementos básicos da composição da imagem, e descobre como contar uma história através da fotografia, é importante refletir sobre os conteúdos. O meio fotográfico se transforma assim em um importante instrumento que permite a formação em conhecimentos transversais, relacionados à educação para a cidadania, à solidariedade e ao respeito a grupos culturalmente diferentes.

Um dos elementos básicos da formação social e cidadã baseia-se na convivência em ambientes multiculturais. A integração em salas interculturais é tão somente uma mostra do que as crianças vão encontrar na sociedade contemporânea. 
comunicação \& educação • Ano XV • número 3 • set/dez 2010

A fotografia permite, em primeiro lugar, observar elementos como diferenças físicas, diversas formas de viver, e assim o professor pode introduzir conceitos relacionados à diversidade cultural. E, por outro lado, graças à fotografia os pequenos têm a possibilidade de observar interações multiculturais efetivas e pacíficas, e assim obtêm um modelo de convivência positivo.

Nessa linha, os objetivos propostos foram os seguintes:

- Utilizar a fotografia como elemento de testemunho do mundo contemporâneo.

- Utilizar a fotografia como recurso para explicar ambientes culturais diferentes daquele da criança.

- Utilizar a fotografia para a aquisição e fomento de valores e atitudes de compreensão, tolerância, respeito às várias culturas que convivem em nosso entorno.

Para tanto, procuraram-se materiais didáticos simples, como um mapa-múndi, um quadro de cortiça, livros e revistas com fotos de crianças, mulheres e homens de diversas origens e procedências culturais, assim como outras onde se pudesse ver uma convivência multicultural, isto é, onde as minorias culturais aparecessem integradas e convivendo de forma respeitosa.

A partir da observação das fotografias, os participantes do curso elaboraram em pequenos grupos um mural com recortes de revistas que foram pregando em cartolinas. Em cada um destes murais deveriam escrever, também, uma frase que aludisse à interculturalidade, à paz e ao respeito mútuo. Elementos relacionados ao idioma, à alimentação, à música, aos costumes ou à religião possibilitaram interessantes comentários sobre a riqueza cultural do universo. A partir do modo de se vestir, o tipo de casa, a forma de posar diante da câmera e outros elementos visíveis nas fotos, foi possível refletir sobre semelhanças e diferenças entre as culturas. Os pequenos perceberam que, se não fosse pelas fotografias, dificilmente poderiam conhecer muitas daquelas realidades tão distantes.

Se considerarmos, de acordo com Van Dijk, que "o racismo não é inato. O racismo é aprendido", podemos defender a ideia de que a fotografia pode constituir uma importante ferramenta que permita à criança tomar consciência dos aspectos multiculturais da sociedade contemporânea. A invisibilidade de alguns grupos étnicos no entorno cotidiano infantil, tal como nas narrações mais extensas (como os filmes da Disney, nos quais as princesas e príncipes costumam ser caucasianos), faz com que existam minorias quase invisíveis para os pequenos. Por isso, o protagonismo em uma fotografia e a reflexão em relação a seu lugar de procedência e seus traços de identidade cultural contribuirão para evitar essa invisibilidade que termina conduzindo ao racismo e à xenofobia.

A fotografia permite uma viagem imaginativa que leva a criança a sentir

9. VAN DIJK, T., apud CASTIELLO, Chema. Los parias de la tierra: inmigrantes en el cine español (Os marginais da terra: imigrantes no cinema espanhol). Madrid: Talasa Ediciones, 2005. p. 11 curiosidade pelas diversas formas de vida e manifestações culturais diferentes das suas, a conhecer algo sobre os movimentos migratórios e suas causas e a sentir interesse e respeito pelas diferentes culturas presentes na sociedade. Também pode auxiliar na eliminação de preconceitos, atitudes discriminatórias, e a ensinar a conviver com respeito às minorias. 
Para entender uma cultura distinta e propiciar laços de interculturalidade não basta tentar compreender o não semelhante, mas também buscar elementos que unifiquem as comunidades humanas, isto é, tudo aquilo que sirva para relacionar e agrupar, para além do que nos separa. Por isso, outra das atividades da oficina centrou-se na realização de fotografias dos próprios companheiros e na comparação dos traços físicos e outros elementos (formas de se vestir ou calçar, tipos de acessórios) que os diferenciavam entre si.

Também foram comparadas fotografias que mostravam pessoas com elementos culturais diversos, com o objetivo de detectar aspectos físicos ou atividades comuns a todas as culturas (o prazer da criança com a brincadeira, a expressão da afetividade com a família ou amigos, a necessidade de comer, beber ou se abrigar do frio etc.) e outros elementos que as diferenciavam. A busca por traços que unifiquem o ser humano deve ser conciliada com a observação de que os demais traços servem para marcar a diversidade física ou cultural dos povos do mundo.

Os resultados dos conteúdos das oficinas orientadas ao descobrimento de outras culturas foram extremamente positivos, já que todos os participantes, a partir da observação de várias fotografias, manifestaram grande curiosidade pela forma de viver em outros lugares do mundo e refletiram sobre a ideia de que a diversidade cultural é uma riqueza que deve ser entendida sempre de modo positivo. Além disso, perceberam que às vezes as diferenças são somente elementos que têm a ver com a aparência externa. Concluíram que, da mesma forma que acontecia no microcosmo de suas próprias salas de aula (onde há companheiros de nacionalidades distintas), na sociedade todas as pessoas têm elementos que as diferenciam das demais e outros que as tornam bastante parecidas.

\section{CONCLUSÕES}

Os resultados das Oficinas de Fotografia Criativa para Crianças foram satisfatórios sob três perspectivas. Em primeiro lugar, evidenciou-se o desenvolvimento de competências nos participantes, orientadas à compreensão de noções vinculadas à linguagem audiovisual, à operação de equipamentos digitais e à criação e produção de imagens fotográficas. Por outro lado, do ponto de vista da pesquisa, o trabalho com crianças de tão pouca idade, no campo específico da fotografia, ofereceu a possibilidade de abordar diversos aspectos de interesse que atualmente estão sendo trabalhos em estudos específicos. Finalmente, o objetivo de aquisição de equipamentos que foi incluído no orçamento da atividade financiada pelo Conselho de Cultura da Junta de Andaluzia (câmeras, computador, impressora fotográfica etc.) foi uma aposta no futuro com a ideia de reproduzir a experiência através de outras oficinas oferecidas em centros educacionais e outros espaços.

O objetivo geral proposto foi cumprido plenamente e, neste sentido, as atividades desenvolvidas demonstram como, ao longo das diversas sessões que foram realizadas, foi possível: 
comunicação \& educação • Ano XV • número 3 • set/dez 2010

10. GUBERN, R. Mensajes icónicos de la cultura de masas (Mensagens icônicas da cultura de massas). Barcelona: Lumen, 1988. p. 24

11. Ver: relato e análise do experimento realizado por meio da fotografia com os huicholes, grupo indígena do México, tradicional e de forte oralidade. Foi possíve estabelecer comparações entre esse povo não submetido aos meios de comunicação e os ocidentais, em relação às formas de conceber figura e fundo, de compor a imagem e de posicionar a câmera. BERKIN, Sarah Corona.

O estudo das formas comunicativas como disciplinas do corpo: o caso da fotografia huichol. Comunicação e educação, São Paulo, v. 11, n. 2, 2006. Disponivel em: <http:// www.revistasusp.sibi.usp. $\mathrm{br} / \mathrm{scielo}$.php?script=sci arttext\&pid = S0104 $-68292006000200007 \& \ln$ $\mathrm{g}=\mathrm{pt} \& \mathrm{nrm}=\mathrm{iso}>$. Acesso em: 15 jul. 2010.
- Estimular a criatividade artística das crianças como parte fundamental de seu desenvolvimento integral.

- Diferenciar os elementos que compõem a imagem fotográfica e aprofundar a importância estética da composição.

- Possibilitar que as crianças tivessem de forma independente uma primeira aproximação aos equipamentos digitais.

- Valorizar a importância da fotografia na formação de códigos, sinais de identidade e elementos distintivos de uma cultura.

- Apreciar o valor da imagem fotográfica como fonte de prazer estético e como parte integrante do patrimônio cultural, contribuindo ativamente para seu respeito, conservação e divulgação.

Ao longo das semanas ficou evidente como as crianças foram aprendendo a ler imagens fotográficas, descobrindo nelas o seu aspecto artístico, assim como suas potencialidades informativas e de comunicação. Elas também se tornaram autoras das próprias fotografias, desenvolvendo critérios de enquadramento (recortar o espaço), seleção de temas, composição harmônica etc. Da mesma forma, interiorizaram e operaram de maneira notável (levando-se em conta a pouca idade da maioria delas) noções como as de ângulo picado, contrapicado, planos, perspectivas e regras de composição. Entenderam ainda noções de iluminação: luz natural, artificial, qualidade e direção da luz, entre outras.

Outro tema tratado foi o da conexão com outras artes, o jornalismo, a publicidade, o teatro e o cinema, que, em não poucos momentos, têm estreita relação com a fotografia. O catedrático Román Gubern aponta que: "A escolha da fotografia como ponto de partida para uma reflexão sobre os meios de comunicação de natureza icônica não é de modo algum um capricho"10. Para ele, o estudo da fotografia deve estar no início de todas as reflexões sobre os meios de comunicação. Contando histórias através de imagens, as crianças aprenderam aspectos da narrativa audiovisual, como o da sequência. Os pequenos participantes, com as limitações inerentes à idade, refletiram sobre como a fotografia está presente na vida cotidiana, comprovando, a partir de sua própria experiência, como a celebração de acontecimentos importantes dos grupos sociais e familiares constitui um dos usos mais importantes da fotografia. Para tanto, trouxeram fotos deles mesmos quando bebês, de seus pais e irmãos, família, férias etc., que descreveram aos colegas e colocaram em um mural, o qual ficou exposto na sala de aula. Também se aproximaram de outras culturas através da fotografia, criando murais de grande criatividade. Neste sentido, a fotografia demonstrou ser um instrumento eficaz de aproximação a outras formas de vida e manifestações culturais, estimulando nas crianças o interesse, o valor e o respeito pelas culturas presentes no entorno em que vivem ${ }^{11}$.

Do ponto de vista técnico, as crianças conheceram o funcionamento de uma câmera fotográfica, operando-a de forma individual nas diversas sessões, de modo autônomo e com destreza. Do mesmo modo, tiveram que dividir o equipamento com um companheiro, já que trabalhavam em duplas, de forma 
Fotografia criativa para as crianças - M. Alvarado, V. Galán, I. Álvarez e J. Carrero

tal que a cooperação e o trabalho conjunto foram estimulados. Muitas das crianças já haviam tido a experiência do uso de câmeras do mesmo tipo ou de telefones celulares, o que mostra que estamos diante de uma geração de pequenos cidadãos digitais cada vez mais acostumados com o fato de que a tecnologia faz parte de seu cotidiano.

Em cada uma das sessões das oficinas de fotografia foi distribuído um manual teórico que explicava, de modo acessível, os conceitos que seriam trabalhados. Também as atividades realizadas implicaram o desenvolvimento de diferentes materiais de apoio. Cada aula contou com gravações em vídeo por parte das professoras e com um registro fotográfico das atividades. Com tal material foram elaborados, finalmente, dois vídeos, projetados em uma sessão posterior no Colégio José María del Campo. A experiência teve ainda uma importante cobertura na imprensa escrita, no rádio e na televisão. O programa Clube de ideias [El Club de la ideas], transmitido pelo Canal Sur Televisión, cobriu amplamente as oficinas e a mostra fotográfica. A notícia da inauguração da exposição foi transmitida também em diferentes telejornais.

Outro aspecto essencial dessa experiência teve a ver com o valor das novas tecnologias para mostrar o trabalho contínuo nas oficinas, tanto para a família, para os professores, como para os próprios participantes. Dessa forma, criou-se um blog, através do qual era possível seguir cada uma das sessões e ver as imagens produzidas pelos pequenos e pelas professoras. O blog se chamava Oficina de Fotografia Criativa para Crianças [Taller de Fotografía Creativa para Niños y Niñas] (<http://tallerdefotografiainfantiladmira.blogspot.com/ >). Esse espaço na internet foi muito bem recebido e contou com diversos acessos e comentários dos representantes, professores das oficinas e do próprio Colégio José María del Campo e da Faculdade de Comunicação.

\section{REFERÊNCIAS BIBLIOGRÁFICAS}

BERGER, J. Modos de ver. Barcelona: Gustavo Gili, 2007.

CAMPS, V. La educación en medios, más allá de la escuela (A educação através da mídia, além da escola). Revista Comunicar, 32, 2009.

CASTIELLO, Chema. Los parias de la tierra. Inmigrantes en el cine español (Os marginais da terra: imigrantes no cinema espanhol). Madrid: Talasa Ediciones, 2005.

COLECTIVO, Amani. Educación Intercultural. Análisis y resolución de conflictos. (Educação intercultural: análise e resolução de conflitos). Madrid: Editorial Popular, 1994.

ENCABO, E. y JEREZ, I. La dramatización como arte creativa: los cuentos de Hans Christian Andersen y la Didáctica de la Literatura (A dramatização como arte criativa: os contos de Hans Christian Andersen e a didática da literatura). Primeras Noticias: revista de Literatura, 209, 2005. 
comunicação \& educação • Ano XV • número 3 • set/dez 2010

ENCABO, E. y LÓPEZ VALERO, A. (Coord.). Didáctica de la literatura: el cuento, la dramatización y la animación a la lectura (Didática da literatura: o conto, a dramatização e a animação para a leitura). Barcelona: Octaedro Editorial, 2004.

GONZÁLEZ R. Arnáiz, G. La interculturalidad como categoría moral (A interculturalidade como categoria moral). In: VV.AA. El discurso intercultural. Prolegómenos a una filosofíaintercultural (Odiscurso intercultural:prolegômenos a uma filosofía intercultural). Madrid: Editorial Biblioteca Nueva, 2002.

GRUPO Crit. Claves para la comunicación intercultural (Chaves para a comunicação intercultural). Castellón de la Plana: Universidad Jaume I, 2003.

GUBERN, R. Mensajes icónicos de la cultura de masas (Mensagens icônicas das culturas de massa). Barcelona: Lumen, 1988.

RODRIGO ALSINA, M. La comunicación intercultural (A comunicação intercultural). Barcelona: Anthropos, 1999.

RODRÍGUEZ BARBERO, A. Didáctica de la fotografía: enseñanza de la fotografía en los niveles de Educación Infantil y Primaria (Didática da fotografia: ensino de fotografia na Educação Infantil e Primária). Revista de Educación de la Universidad de Granada, 14, 2001.

\section{Endereços eletrônicos}

BERKIN, Sarah Corona. O estudo das formas comunicativas como disciplinas do corpo: o caso da fotografia huichol. Comunicação e Educação, São Paulo, v. 11, n. 2, 2006. Disponível em: <http://www.revistasusp.sibi.usp.br/scielo. php?script=sci_arttext\&pid=S0104-68292006000200007\&lng=pt\&nrm=iso $>$. Acesso em: 21 jul. 2010.

MUÑIZ, C. y IGARTÚA, J. J. Encuadres noticiosos e inmigración. Un análisis de contenido de la prensa y televisión españolas [versión electrónica] (Enquadramentos jornalísticos e imigração: uma análise de conteúdo da imprensa e da televisão espanholas [versão eletrônica]). ZER, 16, 2004. Disponível em: <http://www.ehu.es/zer/zer16/articulo_6.htm>.

TALLER DE FOTOGRAFÍA Creativa para Niños y Niñas (Oficina de fotografia criativa para crianças). Disponível em: $<$ http://tallerdefotografiainfantiladmira. blogspot.com/> 